INTERNATIONAL DESIGN CONFERENCE - DESIGN 2018

https://doi.org/10.21278/idc.2018.0376

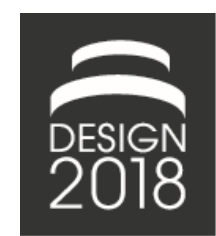

\title{
DESIGN THINKING CAPABILITY MODEL (DTCM): A FRAMEWORK TO MAP OUT DESIGN THINKING CAPACITY IN BUSINESS ORGANISATIONS
}

\author{
D. De Paula, F. Dobrigkeit and K. Cormican
}

\begin{abstract}
It has been suggested that organisations can derive value from a design thinking (DT) capability. However, there is still a very limited understanding of how to integrate and assess DT strategy. Our study aims to develop a conceptual framework - Design Thinking Capability Model (DTCM) - to map out the DT capability in business organisations. The model was developed based on an exploratory research design combining empirical investigations and industry practice. This study can lead to valuable insights into how having a DT strategy can support competitive advantage in organisations.
\end{abstract}

Keywords: design thinking, design management, innovation management, capability

\section{Introduction}

Design thinking (DT) has been heralded as a well-suited methodology for encouraging innovation and economic growth. In particular, prior research has demonstrated that design thinking offers a potent way to create breakthrough products because of its ability to find unarticulated needs and solve problems (Perks et al., 2005; Beverland and Farrelly, 2007; Brown, 2008). For a long time, design thinking was considered the creative activity whose aim was to determine aesthetic features of objects, however; many authors suggest that design thinking can provide significant value to innovation and management (Rosensweig, 2011; Micheli et al., 2012; Carlgren et al., 2014; Liedtka, 2015). Thereby, it seems that the role of design thinking has shifted from a tactic level function to a more elevated strategic position in organisations. However, research on how companies organise and manage design thinking strategy is still very limited.

Scholars argue that design thinking can enable the expansion of an organisation's innovation capabilities because of its ability to include non-designers in the design process (Rosensweig, 2011). Thereby, it has been suggested that organisations can derive value from a design thinking capability, but to generate the most value, design thinking must be strategically supported and integrated. We define design thinking capability as the company's ability to deploy design practice to support its innovation efforts on strategic and functional levels. Researchers argue that it is necessary to understand how design thinking is implemented in practice to assess its impacts and facilitate its integration within the company (Rauth et al., 2014). Recent evidence suggests that mapping a company's design thinking strategy would offer an opportunity to compare different performance results and therefore enhance the value of design thinking for an organisation (Rosensweig, 2011). There are still only a few empirical studies on the actual use of design thinking in companies, and very limited understanding of the potential benefits of implementing DT and its effects on organisations. Most studies in the field of design thinking capability have only focused on specific contexts, such as design thinking implementation for software development (Lindberg et al., 2011), and tools and techniques for product development (Carlgren et al., 2014). A 
more managerial approach is necessary to investigate a company's design thinking situation to uncover gaps between the present, regarding design practice, and where the company wishes to be in the future. Storvang et al. (2014) provided an analysis of how to map out a design capacity in organisations by using five dimensions captured in a Danish context. Our research builds on the model proposed by Storvang et al. (2014), however; all dimensions were adapted to a design thinking context. Therefore, this study aims to develop a conceptual framework - Design Thinking Capability Model (DTCM) - to map out the design thinking capability in business organisations. The model was developed in three phases by using an explorative research design combining previous research, empirical investigations and industry practice.

This study adopts good practices and procedures (Charmaz, 2014) in order to allow a deeper understanding of the current theoretical and practical scenario of design thinking implementation. First, through an objective, systematic and comprehensive synthesis of the literature on what has a direct impact on the company's ability to build a design thinking capability, a draft model was created. Then, we followed the practices on how to validate models proposed by Moody (2005). In this way, ten semistructured interviews were conducted with design thinking coaches, with at least two years of experience in using DT, from educational organisations in Germany. Based on the feedback collected, the model was enhanced, and ten more interviews were conducted with design thinking professionals from the industry in the USA. The interviewees were individuals responsible for implementing DT in the companies, innovation/research and development (R\&D) managers, coaches and employees with some experience of using DT. Finally, based on a rigorous validation process, the Design Thinking Capability Model was created. The overall model consists of appropriate dimensions to capture a company's fundamental drivers of innovation on strategic, functional and operative levels.

Our contribution consists of offering the first conceptual framework to map out the design thinking capability in business organisations. Furthermore, this research extends our knowledge of how to analyse a company's design thinking strategy, which can clarify where managerial efforts should be concentrated to obtain the desired design thinking practice. This study can lead to valuable insights into how having a design thinking strategy can support competitive advantage in organisations.

The remainder of the paper is structured as follows. Section 2 explores how the role of design thinking in management shifted over the years. Then, Section 3 explains in detail the research methodology for this study. Finally, Section 4 analyses the conceptual model, discusses relevant design dimensions and how to map a company's design thinking capability. Final discussions and implications for research conclude the paper.

\section{Design thinking as a management capability}

The definition of DT has changed over the last decades In literature, DT is described and understood in a variety of ways: a cognitive perspective referring to the creative and explorative activity of design (Cross, 1982; Schön, 1983; Rowe, 1987), as a general theory of design (Buchanan, 1992; Simon, 1996), or as a strategic perspective referring to the strategic process of the organisation and more generally to a managerial capability (Brown, 2009; Micheli et al., 2012; Liedtka, 2015). Figure below sums up the three different perspectives claimed by authors on design thinking.

By the early 1980s, cognitive research was introduced by Schön (1993) and his collaborators who emphasised the role of the designer himself and the importance of the study of design thinking. Overall, researchers who follow this perspective and consider design thinking in terms of a cognitive style primarily explore the individual designer and how design experts make decisions. A second theory on design thinking is referred to as a general theory of design. Researchers adopting this perspective claim that the concept of design thinking shifted from aesthetic modelling to wicked problem solving and proposed the notion that all professionals should be able to design (Buchanan, 1992; Simon, 1996). Recently, in order to encourage innovation and economic growth, researchers are investigating how to use design thinking as an organisational resource to reinvent the entire company's design strategy (Cipolla and Moura, 2012). Liedtka (2015) claims that design thinking improves design outcomes because its tools and attitudes address and mitigate the cognitive biases that strongly impact any creative process and represent flaws that can result in failures. For this study, we followed the theoretical lens of design thinking as an organisational resource with focus on a more managerial aspect. 


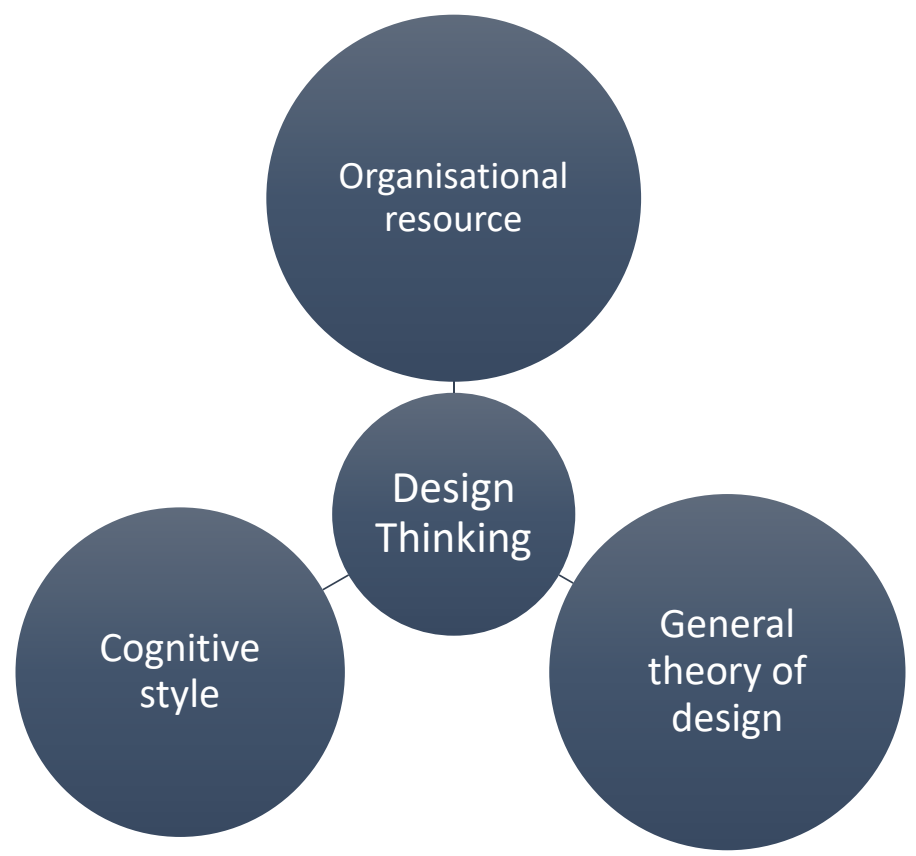

Figure 1. The evolution of design thinking definition

As a strategic and management capability, design thinking has been studied as a way to help address the challenges faced by project managers when creating innovative solutions. Assink (2006, p. 2019) defines the capability to innovate as: "the internal driving energy to generate and explore radical, new ideas and concepts, to experiment with solutions or potential opportunity patterns detected in the market's white space and to develop them into marketable and effective innovations". We define design thinking capability as the company's ability to deploy design practice to support its innovation efforts on strategic and functional levels. According to Mahmoud-Jouini et al. (2016) as a strategic capability, design thinking can provide significant contributions to the challenges encountered by project management in terms of exploration, stakeholder involvement, and firm strategising.

Researchers investigating how organisations promote innovation capabilities to generate value have pointed out the importance of building multidisciplinary skills and encouraging collaboration - evidence of some skill at design thinking (Rosensweig, 2011). Mahmoud-Jouini et al. (2016) claim that design thinking emphasises the need to involve the various stakeholders in the innovation process and proposes methodologies, tools, and processes for easing their interactions. The focus on collaboration through cross-functional teams associated with DT is seen as enhancing collective creative problem solving by bringing to conversations diverse points of view (Carlgren et al., 2016).

Recently, systematic field work has begun to emerge that seeks to explore the use of design thinking methodologies in practice in business organisations. Carlgren et al. (2016) discuss the challenges of using design thinking in industry and Seidel and Fixson (2013) analyse how novice multidisciplinary teams make use of the DT method. Additionally, Carlgren and Rauth (2017) have presented a culture fit tool to investigate how companies can implement and scale design thinking.

Considering the evidence provided, it seems that design thinking is being integrated more as a culture attribute than a specialised expertise. Even though it has been suggested that organisations could value from a design thinking management capability, there is still very limited understanding of how to comprehensively integrate and assess design thinking strategy. Consequently, this limited understanding can lead to companies implementing DT for the wrong reasons or with wrong expectations. In light of this, the goal of our research is to develop a conceptual model - Design Thinking Capability Model (DTCM) - to map out the design thinking capability in business organisations. 


\section{Research method}

This study followed a rigorous three-step approach of development and validation: i) initial exploration, ii) theoretical comparison and iii) final validation. Our approach ensured that our framework was a representative combination of both empirical studies and practices conducted in the industry.

\subsection{Initial exploration}

Before developing a framework to map design thinking strategy, it was imperative to understand the relevant dimensions of design thinking value. Thereby, this phase aimed at conducting an explorative study with design thinking experts in order to formulate propositions and identify key insights on the design thinking contribution to business organisations.

Step one involved the completion of an initial semi-structured interview with ten design thinking professionals (coaches and program leads) from three educational programs in Germany. Respondents were recruited for the study via email and selected based on their experience. The criterion to select the interviewees was based on their level of experience with design thinking. All those interviewed had a detailed knowledge of the design thinking process due to on-going involvement in implementing and/or teaching the process.

The interview questions were adapted from Bohlmann et al. (2013). Interviews typically lasted 30 minutes and were recorded for subsequent analysis. The interviews were analysed using an iterative process of coding and refinement to identify core themes (Charmaz, 2014). First, we analysed the contribution of design thinking to organisations according to the interviewees' definition of design thinking. The definitions investigated are consistent with Brown (2009) who also believes that design thinking is about using designer's sensibility and methods to match people's needs with what is technologically feasible and viable. In addition, we identified dimensions related to the design thinking contribution to organisations: teamwork and people's need.

Table 1. Initial dimensions

\begin{tabular}{|c|c|}
\hline Dimension & Justification \\
\hline 1. Teamwork & $\begin{array}{c}\text { To investigate who is involved in the design } \\
\text { thinking-related activities }\end{array}$ \\
\hline 2. People's need & To uncover hidden needs \\
\hline
\end{tabular}

From the interviewee's perspective, the core of design thinking is about developing empathy to understanding people's feelings and behaviours. As a human-cantered approach, design thinking guides the team to connect more deeply with users and non-users in order to discover opportunities for innovation. Additionally, the greatest contribution of design thinking identified was centred on teamwork. Design thinking is not only for designers. Ideally, a design thinking team should be composed of people with different backgrounds from different departments in the company. The idea behind combining people who were supposed to work on the product in different stages is to make them familiar with the product concept at the early stages of the development. By doing that, the project moves from an individualistic way of thinking to a culture of shared creation, which has the potential to result in more innovative solutions.

\subsection{Theoretical comparison}

To compare the data from the interviews to the literature, the dimensions were re-analysed. We used a constant comparative method of data analysis, which consists of iterative sessions of the recorded interview, each time going deeper into the material to note connections, patterns, and juxtapositions. The constant comparative analysis is the process of comparing the similarities and differences between the categories that emerged from the data collected (Harding, 2013). The outcome of this phase was the addition of five new dimensions: design thinking implementation, user's involvement, frequency of user's involvement, design thinking strategy and design thinking capability. The dimensions identified in the previous phase were renamed to design thinking awareness (teamwork) and the importance of DT 
in the fuzzy front-end (people's need). Following this new analysis, it was concluded that one more phase would be necessary to validate the new dimensions.

\subsection{Final validation}

In order to validate the dimensions, we followed good practices proposed by Moody (2005). A final set of semi-structured interviews (see Appendix) were conducted. Ten design thinking experts, who have experience with both academia and industry, from companies based in the USA were interviewed. The interviews lasted 60-120 minutes and were recorded and transcribed for analysis. For this phase, open coding was used with the help of the qualitative analysis software NVivo. The interviews were coded and labelled according. Finally, emerging patterns were structured into more general categories that helped to refine the dimensions and define key concepts. Figure below summarises the final dimensions captured as a result of our analysis.

Overall, our approach consists of three phases: the understanding of how DT adds value to business organisations, the creation of the framework through comparative analysis and the validation and refinement of the framework. In the next section, we present the model and discuss its dimensions in detail.

\section{The DTCM model}

Based on our analysis, we developed a framework to map out how widespread the integration of design thinking appears in the organisation. The overall framework consists of five dimensions founded on empirical evidence and industry practice in terms of design thinking's contribution to business organisations - design thinking implementation, collaboration, user's involvement, the importance of design thinking in the front-end phase of the development process and design thinking strategy. Each dimension has a five-item scale that companies can use to map their current design thinking situation and clarify where managerial efforts should be concentrated to obtain the desired design practice. The next sections discuss the dimensions in detail.

\subsection{Design thinking implementation}

Design thinking can be implemented in many different ways, such as mind-set, iterative process, linear process or only some specific tool/techniques. Design thinking as an iterative process is when there is a process in place to serve as a guide for the teams and the team is experienced enough to use it in an iterative way, whereas in a linear process the team follows the process step-by-step without flexibility. Design thinking as mind-set describes when the company has the work attitude towards creative problem solving based on the following five principles: user focus, problem framing, experimentation, visualisation and diversity (Carlgren et al., 2016).

The literature has perceived design thinking practices as a powerful tool to create breakthrough products and promote the success of organisations. According to Liedtka (2015), the benefits of using design thinking for product development are many. For instance, benefits include more collaborative effort, positive effect on idea generation, superior product or service and products are more readily adopted by users due to greater product appropriateness. Additionally, applying design thinking to new product development can result in more useful, original, and appealing product concepts.

The first dimension of our model focuses on how design thinking is implemented in the organisation. This dimension is particularly relevant due to the importance of understanding design thinking as a practice potentially valuable for improving innovation outcomes (Liedtka, 2015). In terms of industry, as one of the interviewees mentioned; "I think we started initially thinking it more like tools and techniques and then as a process". In line with practice and theory, the scale progresses from "our company implements design thinking as a mind-set" to "our company doesn't implement design thinking". This dimension aims to capture to which degree a company implement design thinking on a 5 -item scale. 


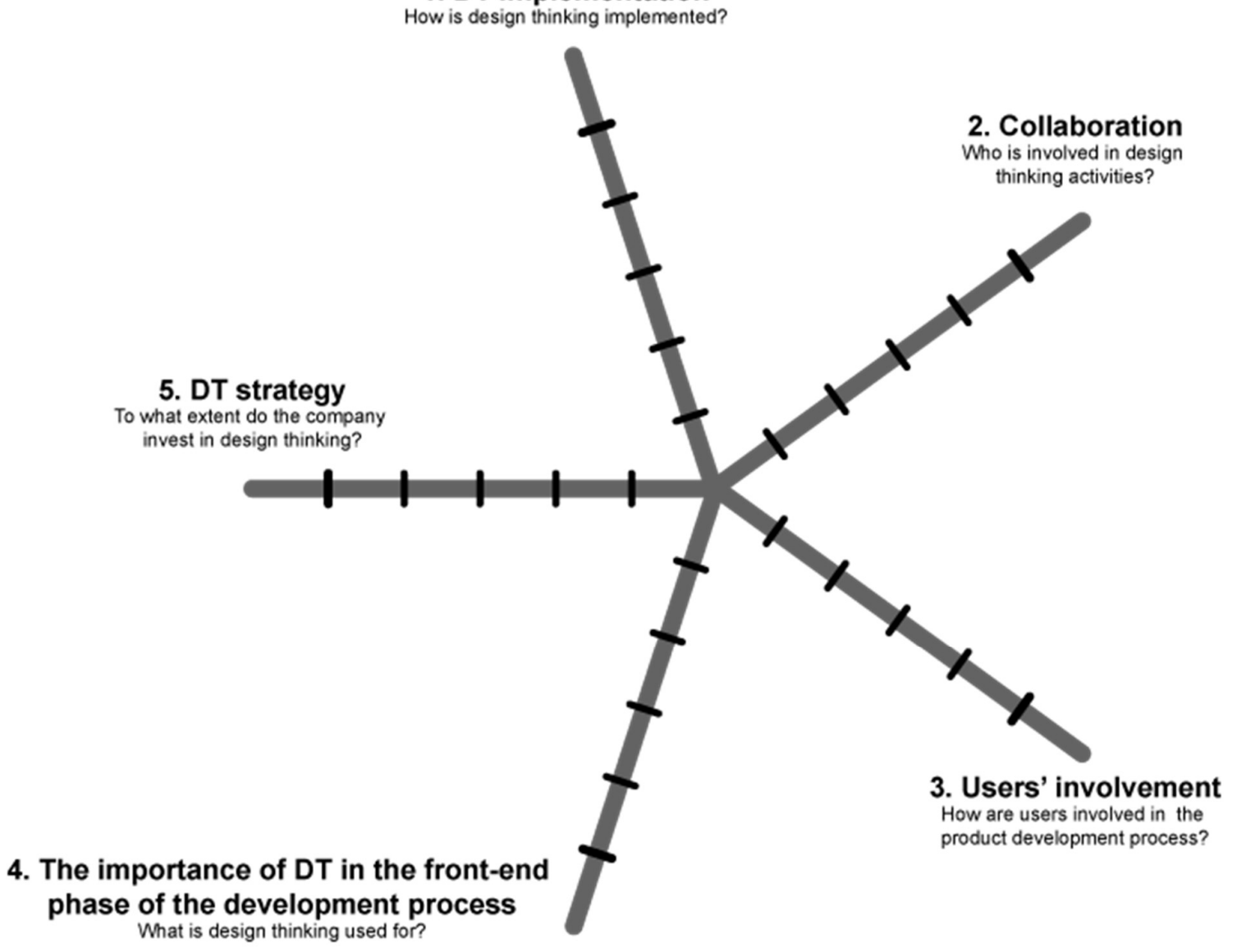

Figure 2. The Design Thinking Capability Model (DTCM)

\subsection{Collaboration}

A common perception of DT is its ability to promote team collaboration. Many companies encourage different cultures in terms of design thinking collaboration. In some cases, it's possible to see crossfunctional teams collaborating or just intra-department collaboration. Cross-functional indicates that different departments are collaborating, such as engineering and marketing. Intra-department is when members of the same department are collaborating, such as members of the design department. Collaboration could also happen on a cross-project level, which refers to when team members can collaborate with members from other projects.

This dimension was created because one of the main contributions of DT is to support team collaboration in order to have a common language. As one interviewee said: "Once you teach everyone design thinking, which is fundamentally focused on the user need, we have a common language to talk about (...) so design thinking overcomes the semantic gap where we don't share common languages".

Similarly, Carlgren et al. (2014) mention that collaboration can promote better team dynamics in terms of increased energy, inspiration and motivation and a significant reduction in the classic divide between functions such as engineering and design. A similar approach is suggested by another interviewed who commented, "Organisations that are typically late, are teams that are not collaborating well". This view is supported by Simons et al. (2011) who claim that having the entire team involved in decisionmaking and discussion creates more robust ideas, fewer design flaws and an easier product to support. For this dimension, our scale progresses from "there are employees collaborating in design thinking activities throughout the organisation" to "there is no collaboration in terms of design thinking-related activities. Our aim is to investigate how widespread design thinking is in the company in terms of 
collaboration. This dimension is in line with data collected from both the interviews and literature. From the data collected, one of the interviewees said, “(...) team fighting and picking the wrong product are the two major reasons start-ups fail and probably are the major reasons projects in large companies fail too. Thereby, it has been demonstrated that the level of employees' interaction has the ability to build trust and intimacy. In turn, intimacy promotes frequent conversations, early sharing of ideas (where others can build on the thoughts) and builds trust, which could increase inventiveness and vitality of ideas (Simons et al., 2011).

\subsection{User's involvement}

Having users' involvement is critical during the development process and it's highly supported by design thinking literature and practice. Research claims that greater user inclusion within the design process results in a better solution (Wilkinson and De Angeli, 2014). Kallmann (2000) stresses the need to engage the users in the early stages of the design process as the way in which they interact with existing products can be used to identify problems and can spark creativity. Similarly, one of the interviewees mentioned that, "it's very important to capture the quality of the interaction". This is in line with Storvang et al., (2014), who point out the need to understand the difference between retrieving information from users (e.g., through questionnaires) and involving users in co-design processes and validation of design solutions in terms of the quality of information collected. Furthermore, Kim and Baek (2011) believe that it is through careful insight into customers' minds that a business can improve its product and its revenue.

In light of this, this dimension aims to identify to what extent users are involved in the company's product development process. Our scale progresses from "our company has a user community that we can reach out to" to "there are no users involved in the development process".

\subsection{The importance of design thinking in the front-end phase of the development process}

Design thinking can be a driver for innovation, and it can take place at different stages in the company, the front-end phase being the most important. Front-end consists of those activities that are conducted prior to actual development. It has been argued that it's vital to pay close attention to this phase as it could lead to saving the most time at the lowest cost later on. The different phases covered during the early stages of the concept development phase: product vision, solution design, opportunity mapping and customer insights (Koen et al., 2001; Seidel and Fixson, 2013).

Product vision refers to when design thinking is relevant to identify the necessary product attributes to meet customer needs, solution design captures the relevance of design thinking to identify how an idea/concept may align customer needs, organisational competencies, and business goals. Opportunity mapping analyses the relevance of design thinking in identifying unarticulated customer needs, whereas customer insight explores the relevance of design thinking in identifying behaviours and attitudes that drive consumers and shape their cultures and communities. According to Markham (2013), the more thoroughly these activities prepare an idea, the better that idea should perform later on the next phases, and ultimately, in the marketplace. Therefore, it's imperative to understand how design thinking can help enhance the outcome of activities carried out at the earliest stages of conception.

For this dimension, our scale progresses from "design thinking is used throughout the fuzzy-front end to identify the necessary product attributes to meet customer needs" to "design thinking is not used during the fuzzy front-end of the development process in our organisation.

\subsection{Design thinking strategy}

It has been suggested that an important element of studying design capability is finding out where it originates in the company (Storvang et al., 2014), and to achieve that this dimension aims to identify the company's strategy in terms of design thinking strategy. According to Rosensweig (2011), it's necessary to analyse the effectiveness of design thinking in building a design capacity in support of a sustained competitive advantage in organisations. Additionally, Valencia et al. (2013) claim that identifying the variety of roles that designers can fulfil in companies is pivotal to support the strategic 
utilisation of design, and to strengthen their product development processes. In order to spread design thinking, some companies make investments in different strategies such as the train the trainer program, creating a collaborative creative space, encouraging workshops/mentoring and/or acquiring basic resources. Train the trainer refers to when the team has the competence to train inexperienced members of the team, collaborative creative space captures when the team has access to collaborative spaces. Workshops/mentoring discusses when the team has access to relevant training, whereas material is when the team has access to basic resources (post-its, whiteboards) necessary to perform some DT-related activities. For this dimension, our scale progresses from "our team has access to training, coaching, space and resources" to "design is not seen as an important competence in our organisation".

\section{Discussion}

This study aimed to develop a conceptual model - Design Thinking Capability Model (DTCM) - to map out the design thinking strategy in business organisations. Through an explorative research design combining empirical investigations with industry practice, we identified five relevant dimensions in terms of where design thinking adds value to business organisations: design thinking implementation, collaboration, user' involvement, the importance of design thinking in the front-end phase of the development process and design thinking strategy. These dimensions are all in the scope of design management and product development literature (Micheli et al., 2012; Liedtka, 2015). All five dimensions were integrated into a framework to illustrate strategic elements that could be measured in order to achieve better product performance results. First, we propose that mapping the design thinking capability in business organisations could offer managers the opportunity to understand the current company's design thinking situation, uncover gaps in the strategy implemented, and determine where it wishes to be in the future. Additionally, the framework presented in this study could be used to analyse how companies sense and respond to emerging needs in order to create new value by adopting a design thinking dynamic capability. Similar to Storvang et al. (2014), we do not claim that companies far from the centre are in better position for design thinking capability than those nearest the centre. In particular, companies can take advantage of the map to compare different performance results and therefore, establish when and how to move back and forth in order to achieve better results. Our findings shed new light on the complexity of adopting design thinking as an innovation strategy in business organisations.

\section{Conclusion}

Our paper presented a conceptual framework to map out the design thinking capability in business organisations. By following well-established guidelines of creation and validation of conceptual frameworks, we developed DTCM - The Design Thinking Capability Model. Although we followed a rigorous process to develop our model, it may be necessary to test it in industry cases. Implementing the framework in the industry is beyond the scope of this paper, which can be seen as a limitation. In light of this, as future work, we plan to investigate how our framework could be used by large organisations in order to analyse their design thinking capability.

Our contribution consists of offering the first conceptual framework to map out the design thinking capability in business organisations. A more detailed understanding of how companies organise and manage design thinking strategy can help researchers develop specific measures to accurately assess its outcomes and contributions, which could lead to better product performance. This study can lead to valuable insights into how having a design thinking strategy can support competitive advantage in organisations by facilitating the dialogue on the company's strategic activities and design thinking performance.

\section{Acknowledgements}

This research was undertaken with support from Conselho Nacional de Desenvolvimento Científico e Tecnológico (CNPQ) - Brazil and the Hasso Plattner Design Thinking Research Program. 


\section{References}

Assink, M. (2006), “Inhibitors of disruptive innovation capability: a conceptual model”, European Journal of Innovation Management, Vol. 9 No. 2, pp. 215-233.

Ben Mahmoud-Jouini, S., Midler, C. and Silberzahn, P. (2016), "Contributions of Design Thinking to Project Management in an Innovation Context", Project Management Journal, Vol. 47 No. 2, pp. 144-156.

Beverland, M. and Farrelly, F. (2007), “What Does It Mean to Be Design-led?”, Design Management Review, Vol. 18 No. 4, pp. 10-17. https://doi.org/10.1111/j.1948-7169.2007.tb00089.x

Brown, T. (2008), "Design thinking”, Harvard Business Review, Vol. 86 No. 6, pp. 84-92.

Brown, T. (2009), Change by Design: How Design Thinking Transforms Organizations and Inspires Innovation, HarperBusiness, New York.

Buchanan, R. (1992), "Wicked problems in design thinking”, Design Issues, Vol. 8 No. 2, pp. 5-21.

Carlgren, L. and Rauth, I. (2017), Workshop on: "Matching design thinking with your organisational culture", D.Confestival, Potsdam, Germany.

Carlgren, L., Elmquist, M. and Rauth, I. (2014), "Exploring the use of design thinking in large organizations: Towards a research agenda", Swedish Design Research Journal, Vol. 1 No. 14, pp. 23-32.

Carlgren, L., Elmquist, M. and Rauth, I. (2016), "The Challenges of Using Design Thinking in IndustryExperiences from Five Large Firms", Creativity and Innovation, Vol. 25 No. 3, pp. 344-362. https://doi.org/10.1111/caim.12176

Cipolla, C. and Moura, H. (2012), "Social Innovation in Brazil Through Design Strategy", Design Management Journal, Vol. 6 No. 1, pp. 40-51.

Cross, N. (1982), "Designerly ways of knowing", Design Studies, Vol. 3 No. 4, pp. 221-227. https://doi.org/10.1016/0142-694X(82)90040-0

Kallmann, R. (2000), "Inclusive Design: Excluding Users in a Conscious Way", Proceedings of the Human Factors and Ergonomics Society Annual Meeting, SAGE PublicationsSage CA: Los Angeles, CA, Vol. 44 No. 38, pp. 901-904.

Kim, B. and Baek, J. (2011), "Leading the Market with Design Thinking and Sensibility", Design Management Review, Vol. 22 No. 3, pp. 80-89. https://doi.org/10.1111/j.1948-7169.2011.00143.x

Koen, P., Ajamian, G., Burkart, R., Clamen, A., Davidson, J. et al. (2001), "Providing Clarity and a Common Language To the "Fuzzy Front End."”, Research Technology Management, Vol. 44 No. 2, pp. 46-55.

Liedtka, J. (2015), "Perspective: Linking Design Thinking with Innovation Outcomes through Cognitive Bias Reduction", Journal of Product Innovation Management, Vol. 32 No. 6, pp. 925-938. https://doi.org/10.1111/jpim.12163

Lindberg T., Meinel C. and Wagner R. (2011) “Design Thinking: A Fruitful Concept for IT Development?", In: Meinel C., Leifer L., Plattner H. (Ed.) Design Thinking, Understanding Innovation, Springer, Berlin, Heidelberg pp. 3-19.

Markham, S.K. (2013), "The impact of front-end innovation activities on product performance", Journal of Product Innovation Management, Vol. 30 No. S1, pp. 77-92.

Micheli, P., Jaina, J., Goffin, K., Lemke, F. and Verganti, R. (2012), "Perceptions of industrial design: The "means" and the "ends"”, Journal of Product Innovation Management, Vol. 29 No. 5, pp. 687-704.

Moody, D.L. (2005), "Theoretical and practical issues in evaluating the quality of conceptual models: current state and future directions", Data \& Knowledge Engineering, Vol. 55 No. 3, pp. 243-276.

Perks, H., Cooper, R. and Jones, C. (2005), "Characterizing the role of design in new product development: An empirically derived taxonomy", Journal of Product Innovation Management, Vol. 22 No. 2, pp. 111-127.

Rauth, I., Carlgren, L. and Elmquist, M. (2014), "Making It Happen: Legitimizing Design Thinking in Large Organizations", Design Management Journal, Vol. 9 No. 1, pp. 47-60.

Rosensweig, R.R. (2011), "More than Heroics: Building Design as a Dynamic Capability", Design Management Journal, Vol. 6 No. 1, pp. 16-26. https://doi.org/10.1111/j.1948-7177.2011.00025.x

Rowe, P.G. (1987), Design Thinking, MIT Press.

Schön, D.A. (1983), The Reflective Practitioner : How Professionals Think in Action, Basic Books.

Seidel, V.P. and Fixson, S.K. (2013), “Adopting design thinking in novice multidisciplinary teams: The application and limits of design methods and reflexive practices", Journal of Product Innovation Management, Vol. 30 No. S1, pp. 19-33.

Simon, H. (1996), The Sciences of the Artificial, 3rd ed., The MIT Press, Cambridge, Massachusetts.

Simons, T., Gupta, A. and Buchanan, M. (2011), "Innovation in R \& D: Using design thinking to develop new models of inventiveness, productivity and collaboration", Journal of Commercial Biotechnology, Vol. 17 No. 4, pp. 301-307.

Storvang, P., Jensen, S. and Christensen, P.R. (2014), "Innovation through Design: A Framework for Design Capacity in a Danish Context.”, Design Management Journal, Vol. 9 No. 1, pp. 9-22. 
Valencia, A., Person, O. and Snelders, D. (2013), "An in-depth case study on the role of industrial design in a business-to-business company", Journal of Engineering and Technology, Vol. 30 No. 5, pp. 363-383. https://doi.org/10.1016/j.jengtecman.2013.08.002

Wilkinson, C.R. and De Angeli, A. (2014), “Applying user centred and participatory design approaches to commercial product development”, Design Studies, Vol. 35 No. 6, pp. 614-631.

\section{Appendix: Interview questions}

Questions about design thinking implementation

In what stage of the development process is design thinking normally implemented and how?

Questions about the DT collaboration

Do you believe having a cross-functional team would decrease costs with handover (e.g. time to explain the product concept to the next team) and rework (e.g. errors committed due to the lack of team collaboration)? If yes, why? If not, why not?

Questions about users' involvement

How does the concept development team learn about the users? Do the users participate in the process in the company? Does the team learn about the users through other methods such as surveys, observations, and focus groups? How often does the team meet with the users?

Questions about the front-end phase

What is the role of design thinking to generate and select ideas?

Questions about DT Strategy

What drives your company to use design thinking? If you were asked to develop metrics to prove the usefulness of design thinking in terms of its benefits and cost? What would you do?

Danielly Oliveira De Paula, PhD Student

National University of Ireland Galway, College of Engineering \& Informatics

9A Willow Park, H91 F469 Galway City, Ireland

Email: d.ferreiraoliveiradepaula1@nuigalway.ie 